\title{
INSTRUMENTS TO ACCESS THE CHEMISTRY PEDAGOGICAL CONTENT KNOWLEDGE: AN INTEGRATIVE REVIEW
}

PROBLEMS

OF EDUCATION

IN THE $21{ }^{\text {st }}$ CENTURY

Vol. 79, No. 3, 2021

381

\author{
Rolién J. V. Cirilo, Elaine A. Colagrande \\ Federal University of Alfenas, Brazil \\ E-mail: rolienvieira@gmail.com, elainecola@gmail.com
}

\begin{abstract}
This research presents an integrative review about the methodological procedures adopted in the research of the Chemistry PCK, with the aim of identifying the data collection instruments used to explain the PCK in this field, seeking to observe its frequency of use and also contribute to the advancement of knowledge established by previous reviews. 89 articles published in magazines well evaluated by CAPES were selected, indexed to the Scopus (Elsevier) database. The treatment of the data was based on the technique of content analysis, resulting in six categories constructed a posteriori: a) period of publications; b) country of origin of the research; c) relationship to a specific topic; d) the teaching experience of the target audience; e) research approach and data collection instruments; and f) the use of PCK models as a theoretical framework. The results suggest a methodological predominance of a qualitative nature, with interviews, field diaries, observation of the practice, and questionnaires some of the most used instruments. Besides, a trend related to the specification of topics in the Chemistry discipline can be identified, as well as the lack of clarity regarding the variety of PCK models present in the literature and the failure to adopt these as a theoretical basis in most of the research studies analysed. There is also an express need to investigate the PCK of Chemistry teachers in practice in higher education since the results reinforce the scarcity of papers for this specific audience.
\end{abstract}

Keywords: chemistry teaching, data collection instruments, professional knowledge, teacher training, teacher's knowledge

\section{Introduction}

"Teacher's matter." (Keller et al., 2016, p. 1). This quote was chosen to introduce the theme addressed in this investigation: the importance of teacher professionalization and the teachers' professional appreciation, which has become increasingly clear, more explicit in the academic world. Shulman (1986), when theorizing about the Pedagogical Content Knowledge construct, PCK, defended the need to establish a knowledge base that could influence the teaching professionalization, in addition to specifying the domain of the specific disarticulated content of general pedagogical knowledge.

The development of the PCK construct, in addition to assisting in the initial and continuing training of teachers, as pointed out by Kind (2009) and Fraser (2015), also contributed to a systematized view at the teaching performance, in the form of professionalization of these teachers. Shulman (1986) considers the PCK as an amalgam between General Pedagogical Knowledge (PK) and Content Knowledge (CK), a special form of knowledge that belongs only to professionals in this class and that integrates the most powerful tools of pedagogical performance to making a purely scientific concept pedagogically understandable for students.

The PCK construct is understood in different ways among researchers on the theme, as pointed out by Kind (2009) and Goes (2014). Pena and Mesquita (2020), for example, are based on Shulman's (1986) proposal to define the PCK as an amalgam of all categories of 
Rolién J. V. CIRILO, Elaine A. COLAGRANDE. Instruments to access the chemistry pedagogical content knowledge: An integrative review

PROBLEMS

OF EDUCATION

IN THE $21^{\text {st }}$ CENTURY Vol. 79, No. 3,202

382

the professional knowledge base, in their Pedagogy Content Knowledge Chemistry (PCKC) model. This definition differs from the initial ideas of Shulman (1986), because, according to these authors, Shulman's PCK involves a special form of the teacher's professional knowledge between two knowledge bases (General Pedagogical Knowledge and Content Knowledge) for a certain audience of students, but not to all types of students. This makes them conclude the need to include all knowledge bases to define the PCKC.

PCK models, with different categories of knowledge bases, have been the subject of discussions in the scientific literature (Fernandez, 2015a; Kind, 2009). Shulman (1987) proposed a basis for this knowledge, which includes: content knowledge; general pedagogical knowledge; curriculum knowledge; pedagogical content knowledge; knowledge of the learners and their characteristics; knowledge of the educational contexts; and knowledge of educational ends, purposes and values, and their philosophical and historical grounds. Grossman (1990), Shulman's adviser, proposed a professional knowledge base different from that initially proposed by Shulman. Magnunsson et al. (1999) proposed another basis for the Science Teachers' PCK and, likewise, many other models and knowledge bases have been built over the years. There was a meeting, held in 2012, by about 30 different research groups of PCK in Sciences, in an attempt to define a concept and a consensual model of the PCK, known as the Summit Model. Even so, other models continue to emerge in the scientific literature, such as that of Azam (2019) and that of Pena and Mesquita (2020), for example.

Shulman (2007), in response to a criticism by Evans (2007) regarding the "existing practice" as a way of molding education professionals, explained the importance of investigating teaching practice and investing in teacher training through the "wisdom of practice" as a way to improve professionalization, investigating and systematizing the variance of these practices through PCK research. However, there is still much to clarify about the PCK's explicit processes, which, according to Baxter and Lederman (1999), Kagan (1990), and Kind (2009), appear as something latent, implicit. Loughran et al. (2004) report the difficulty of explaining the teachers' PCK, as well as Fernandez (2015a). Loughran et al. (2004) propose instruments (the CoRe; Content Representation, and the PaP-eRs, Pedagogical and Professional experience Repertoires), to explain the teachers' PCK. These are not the only data collection instruments that have been validated in the literature. Baxter and Lederman (1999) and, later, Kind (2009) revised to compile the most used instruments, as well as to classify them - in the case of Kind in specific research categories. From this scenario, the interest arose in identifying the frequency with which the instruments of data collection and explanation of the PCK are used, the variety, and also updating on the instruments developed in the years after the mentioned revisions.

\section{Research Problem}

Given the context presented by Loughran et al. (2004), Fernandez and Goes (2014), and Fernandez (2015a), it is possible to understand that the PCK, although widespread in research worldwide, proves to be quite complex to investigate and make explicit in teaching practice. As a result, there is still a lack of clarity about the diversity of instruments used to access and document the PCK of teachers from different areas of knowledge, including Chemistry.

\section{Research Focus}

This study has a specific focus on the methodological part of the selected publications, to synthesize the variety of data collection instruments used to access the Chemistry teachers' PCK. 
The aim of this study was to systematize publications involving the Chemistry PCK, from 2001 to 2020, specifying the data collection instruments used to explain the PCK, seeking to identify the frequency of use of these instruments, and seeking to establish a panorama contextualization of these research studies, to expand the results obtained in previous reviews, in addition to enabling a methodological update for the academic community.

Thus, the research questions that guided the realization of this work were:

1. Which nationalities are involved in Chemistry PCK research?

2. Which specific Chemistry topics have been investigated the most in these publications?

3. What is the target audience investigated in these surveys?

4. What are the instruments and how often have they been used to explain the Chemistry teachers' PCK in the selected articles?

5. Which PCK models have been used the most in the selected articles?

\section{Research Methodology}

\section{General Background}

This research adopts a qualitative methodological approach, in the perspective presented by Creswell (2009), in which the questions and procedures emerging from the investigative process are used. From a qualitative perspective, this study can be classified as an integrative review, as Cooper (1982) pointed out:

The goal of an integrative review is to summarize the accumulated state of knowledge concerning the relation(s) of interest and to highlight important issues that research has left unresolved (Taveggia, 1974). From the reader's viewpoint, an integrative research review is intended to (a) replace papers that have fallen behind the research front (Price, 1965) and (b) direct future research so that it yields a maximum amount of new information. (p. 292)

According to Cooper (1982) and Russel (2005), the integrative review research can be consolidated based on results or procedures adopted in several empirical types of research developed in the literature. As an example, it can be mentioned the variety of data collection instruments used in research on the topic of Pedagogical Knowledge of Content in the disciplinary field of Chemistry, a perspective of great interest in this investigation. The context of this research, therefore, involves the theme of the Chemistry PCK so that the methodological procedures used in the analysed articles can be synthesized.

As previously exposed, research on the PCK uses several data collection instruments and there is an enormous difficulty in explaining the PCK of a given subject, as it is something underlying, latent, or implicit for education professionals. It is necessary to clarify some ideas in this field, addressing what they are and how often these instruments are used.

Not only the research instruments but also, as pointed out by Abell (2008), there are discrepancies concerning the PCK concept itself, in which, in this case, the author suggests that the construct is related to a specific topic, as well as the diversification of the PCK models and professional knowledge bases proposed in the literature, which according to Goes (2014), broaden the debates about the very professional teaching of Chemistry teachers. An integrative review survey, therefore, can provide an overview in terms of the methodological variety that has been applied to research on the topic in the selected period. 
Rolién J. V. CIRILO, Elaine A. COLAGRANDE. Instruments to access the chemistry pedagogical content knowledge: An integrative review

PROBLEMS

OF EDUCATION

IN THE $21^{\text {st }}$ CENTURY Vol. 79 , No. 3, 2021

384

Sample

For the composition of the corpus of this research, 130 articles were selected in journals relevant to the area of Education and Teaching. The search took place in the Scopus (Elsevier) database using the terms "PCK" and "Chemical or Chemistry" that could be contained in the title, abstract, or keywords of the articles, in the period from 2001 to 2020. It was chosen for analysing only the articles published by journals with qualifications A1 or A2 in Education or Teaching, according to the classification carried out by the Brazilian government agency CAPES - Coordenação de Aperfeiçoamento de Pessoal de Nível Superior (Coordination for the Improvement of Higher Education Personnel), which resulted in 89 articles selected for analysis.

\section{Instrument and Procedures}

The bibliographic survey was carried out between the months of August and October 2020. Based on a careful reading of the title, summary, keywords, and, when necessary, the full text of the article, a set of information was elaborated, summarized in Table 1.

Table 1

Description of the Collected Data of the Papers Analysed

\begin{tabular}{ll}
\hline Collected data & Objective \\
\hline Year of publication & Establish a temporal overview of the selected articles. \\
\hline Country of origin of the articles & $\begin{array}{l}\text { To verify which countries have contributed to the research in PCK of } \\
\text { Chemistry, as well as the international partnerships established between the } \\
\text { researchers who sign as authors of these articles. }\end{array}$ \\
\hline Methodological Approach & $\begin{array}{l}\text { Identify the methodological approach of each article in qualitative, } \\
\text { quantitative, and mixed approaches. }\end{array}$ \\
\hline Data collection instruments & $\begin{array}{l}\text { Check the variety of instruments used in the articles, as well as their } \\
\text { frequency of use. }\end{array}$ \\
\hline Investigated target audience & Check which audiences have been investigated in the selected period. \\
\hline Topic specifications & Identify, in each publication, the use of one or more specific topics and, also, \\
\hline PCK model adopted & Identify whether a PCK model was adopted as a theoretical framework in the \\
\hline
\end{tabular}

After data collection, the analysis was carried out, as described below.

\section{Data Analysis}

The data were processed using the Content Analysis technique, which, according to Bardin (2011), consists of a technique for analysing the content manifested in the messages, aiming at their objective, qualitative and quantitative description systematically, to later proceed to the interpretation of these communications. Such a means of analysis, in the perspective presented by Bardin, may allow a conception of the manifest content in an exploratory perspective as well as to serve as proof, in a determined investigation, in addition to a merely superficial and emptied understanding. It is at this point - the moment in which it is understood about the manifest content after the analytical treatment - that the author considers the importance of the inferences, made possible by the use of the technique. 
The manifest content of the corpus was analysed from registration units, which are fragments of the text that have been coded. It is understood as a unit of understanding for the units of record, the units of context, which enabled the categorization process.

It is also understood that the categories constructed a posteriori are made up of groupings, by differentiation, of the registration units. And, given the categorization process, the explanation and discussion of the results obtained enabled a more critical, systematic, and in-depth look at the productions that involve the theme of Pedagogical Knowledge of the Chemistry Disciplinary Content, mainly, for the variety and frequency of use of the data collection instruments contained in the corpus.

\section{Research Results}

The analysis of the data started with the fragmentation of the corpus to constitute registration units and, in the case of the present investigation, it can be mentioned, for example, the year of publications as registration units in the "Period of publications" category; the methodological approach and data collection instruments as recording units of the category "Methodological approach and data collection instruments"; and the PCK models, which were adopted or not in the investigations, as registration units of the category "The use of PCK models as a theoretical reference".

This analysis brought out the following categories: a) period of publications; b) country of origin of the research; c) the relationship with a specific topic; d) the teaching experience of the target audience; e) research and data collection approach; and f) the use of PCK models as a theoretical framework.

\section{a) Period of publications}

The distribution of the articles selected by the year of publication is shown in Figure 1. It is possible to notice the absence of publications in the first two years of this time frame, as well as in the years 2006 and 2007. Also noteworthy is the expressive increase in publications in the decade $2011-2020$, this number $(n=69)$ being more than triple the first decade of this cut $(n=20)$, the period 2001-2010.

\section{Figure 1}

The Number of Papers per Year

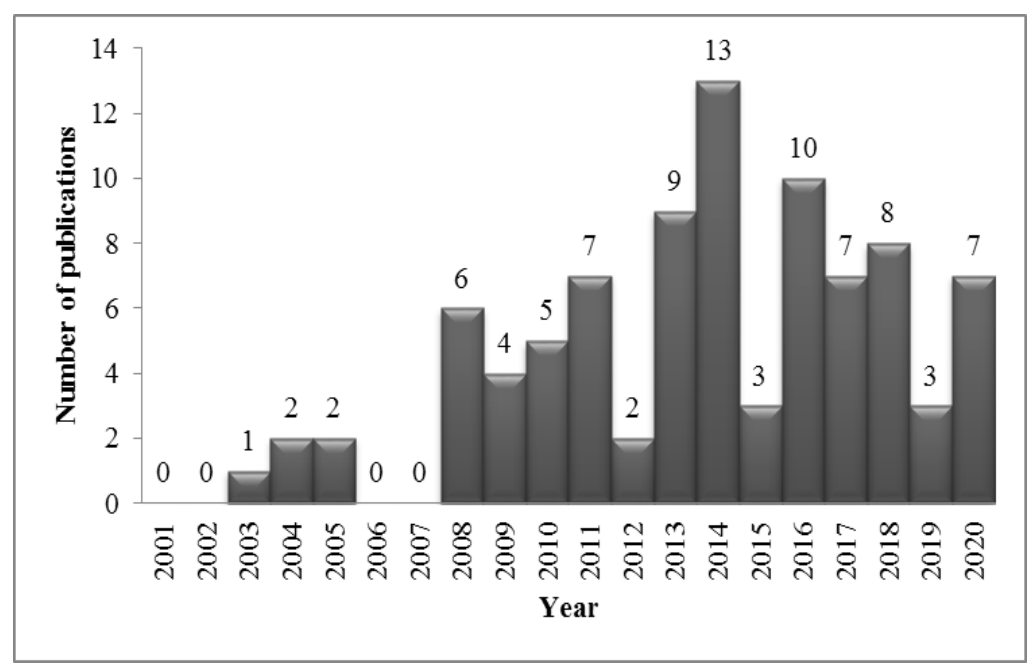


Rolién J. V. CIRILO, Elaine A. COLAGRANDE. Instruments to access the chemistry pedagogical content knowledge: An integrative review

PROBLEMS

OF EDUCATION IN THE $21^{\text {st }}$ CENTURY Vol. 79 , No. 3, 2021

386

b) Country of origin of the research

In this category, the origin of the publications was extracted from the corpus. With that, it was necessary to define two criteria in the categorization: the studies produced by authors from a single country and the consolidated international partnerships between the authors of the same article, which can be seen in Figure 2; and the frequency of contributions from each country, as well as the partnerships established at the international level, shown in Table 2.

\section{Figure 2}

International Partnership and Individual Country Contributions

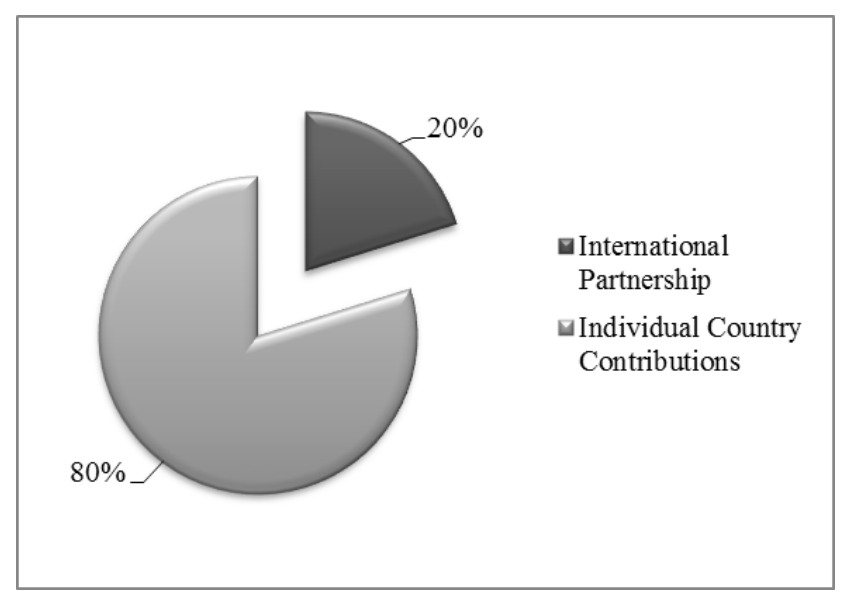

Table 2

The Number of Papers by Country

\begin{tabular}{lll}
\hline Country & $\boldsymbol{N}$ & $\%$ \\
\hline International Partnership & 18 & 20.2 \\
\hline USA & 10 & 11.2 \\
\hline Turkey & 9 & 10.1 \\
\hline South Africa & 7 & 7.9 \\
\hline Brazil & 7 & 7.9 \\
\hline Germany & 5 & 5.6 \\
\hline Finland & 4 & 4.5 \\
\hline Israel & 4 & 4.5 \\
\hline Netherlands & 3 & 3.4 \\
\hline Sweden & 3 & 3.4 \\
\hline Taiwan & 2 & 2.2 \\
\hline Australia & 2 & 2.2 \\
\hline China & 2 & 2.2 \\
\hline Others & 13 & 14.6 \\
\hline
\end{tabular}


The subcategory "Others", shown in Table 2, included thirteen countries (Ireland, Spain, Argentina, Colombia, Mexico, United Kingdom, Thailand, Slovakia, Switzerland, Canada, Slovenia, Indonesia, and Portugal) that contributed individually with 1 paper each. It is also important to note that Croatia and New Zealand participate in the established international partnerships and, in the selected corpus, no individual contribution from these countries to the research in PCK in Chemistry was identified.

It is noted, from these results, that the category with the highest frequency corresponds to the publications developed through international partnerships between researchers of different nationalities $(n=18)$ that make up Table 2. It is also possible to note the significant contribution by part of the USA $(n=10)$, whose construct of the PCK has its origin, and, finally, the worldwide dissemination of these research studies, which has 25 different countries in this corpus.

\section{c) Relation to a specific topic}

The systematization of the PCK of specific topics can approximate Shulman's initial view, in which he considers that the PCK is the pedagogical knowledge referring to specific content. Through the analysis, it was possible to systematize the results obtained from the corpus into two criteria, which can be seen in Figure 3, so that $65 \%$ of the publications $(n=58)$ are related to a specific topic, from which the following topics emerge: chemistry organic; chemical bonds; models, modelling and chemical language; nature of science; chemical balance; nature of the matter; and electrochemistry as the most recurrent among studies.

\section{Figure 3}

Topic-Specific Related Papers on the Corpus

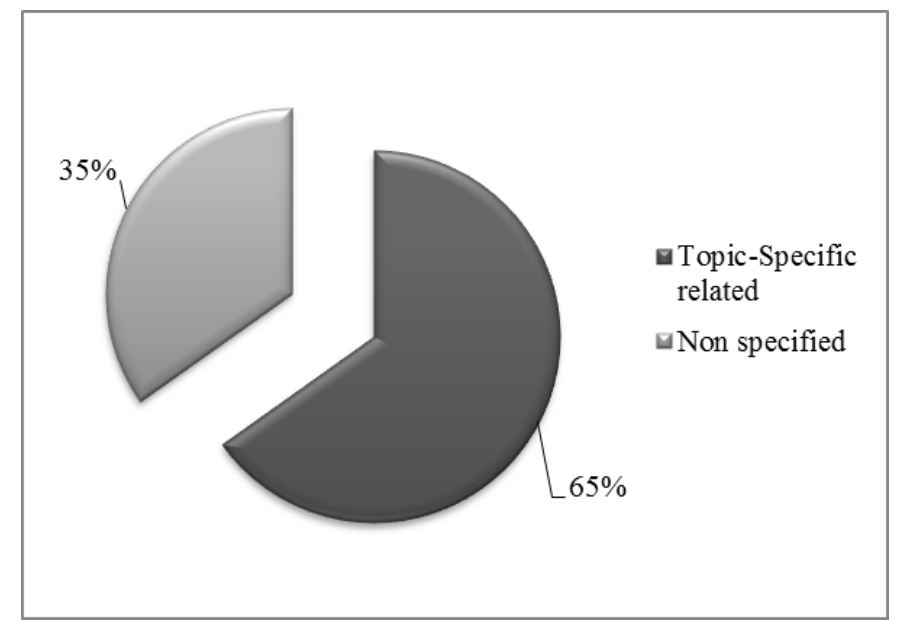

Other topics, less recurring, were also found, such as biochemistry, amount of matter and stoichiometry, chemical reactions, mixtures, solutions and solubility, acids and bases, green chemistry and environmental chemistry, gases, analytical techniques, the periodic table, space, chemistry quantum, nuclear reactions, chemical kinetics, and speed of sound. There are $35 \%$ of the papers in this corpus $(n=31)$ that do not refer to any specific Chemistry topic, addressing broader aspects such as epistemological beliefs, technological knowledge, and the identity of Chemistry teachers, for example. 
Rolién J. V. CIRILO, Elaine A. COLAGRANDE. Instruments to access the chemistry pedagogical content knowledge: An integrative review

PROBLEMS

OF EDUCATION

IN THE $21^{\text {st }}$ CENTURY Vol. 79 , No. 3, 202

388

\section{d) The teaching experience of the target audience}

To evaluate how systematization and documentation of Pedagogical Knowledge of the Content of Chemistry teachers occurs, this category was elaborated, having four defined criteria: teachers in training; teachers working in basic education; in-service teachers in higher education; and mixed audience (of teachers in training and/or in exercise), as shown in Table 3. It is possible to verify that the highest frequency of publications involves teachers in exercise in basic education $(n=38)$, followed by the public in training $(n=32)$ and, finally, the teachers working in higher education $(n=9)$. There are also few publications aimed at studies of a mixed target audience $(n=7)$.

It should also be noted that, based on the corpus, it was not possible to identify the target audience of 3 published articles, one of which was a review article.

Table 3

Teaching Experience

\begin{tabular}{|c|c|c|c|}
\hline \multicolumn{2}{|l|}{ Subjects } & \multicolumn{2}{|l|}{$N$} \\
\hline \multirow{2}{*}{ High school teachers } & Beginners & 3 & \multirow{2}{*}{38} \\
\hline & Experienced & 35 & \\
\hline Pre-service teachers & & 32 & \\
\hline \multirow{2}{*}{ College professors } & Beginners & 1 & \multirow{2}{*}{9} \\
\hline & Experienced & 8 & \\
\hline \multirow{3}{*}{ Mixed subjects } & High school teachers and college professors & 2 & \multirow{3}{*}{7} \\
\hline & Pre-service and high school teachers & 2 & \\
\hline & Pre-service and college professors & 3 & \\
\hline \multicolumn{2}{|c|}{ Not mentioned / Not identified } & 3 & \\
\hline
\end{tabular}

e) Research approach and data collection instruments

The research approach was extracted from the corpus, obtaining the classifications in qualitative research, quantitative research, and mixed research, as shown in Figure 4. There was also an analysis related to the most used data collection instruments in all publications, as well as the most recurrent instruments in each research approach adopted by the authors.

It can be seen, according to Figure 4, that purely qualitative methods are the most used in the investigations $(n=66)$, followed by mixed methods $(n=18)$ and a low frequency of purely quantitative methods $(n=5)$. 
Rolién J. V. CIRILO, Elaine A. COLAGRANDE. Instruments to access the chemistry pedagogical content knowledge: An integrative review

PROBLEMS

OF EDUCATION

IN THE $21^{\text {st }}$ CENTURY

Figure 4

Methodological Approach Used in the Publications

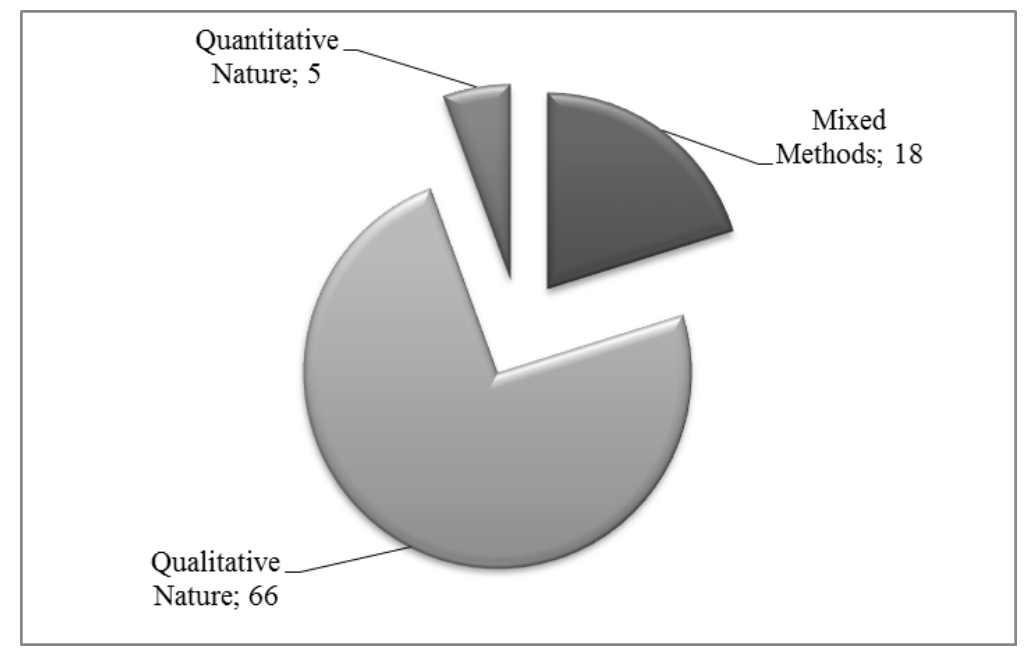

The most recurrent collection instruments identified in the corpus are interviews (open or semi-structured), questionnaires, observation of the practice (observation, audiovisual recording of classes, notes, and field records), Content Representation (CoRe), school documents (plans classes, teachers' artifacts, textbooks, meeting minutes and posters) and field diaries (narratives, experience reports, essays, and reflective records).

According to Table 4, among studies of a qualitative nature, the same previous pattern can be observed, in which interviews are adopted in most publications. It is possible to notice that there are articles that use a single collection instrument and others that use multiple data collection instruments.

\section{Table 4}

Instruments Used According to the Nature of the Research

\begin{tabular}{|c|c|c|}
\hline \multirow{5}{*}{ Qualitative approach $(n=66)$} & Multiple instruments $(n=57)$ & $\begin{array}{l}\text { Most papers }(n=45) \text { use interviews as an } \\
\text { instrument. }\end{array}$ \\
\hline & \multirow{4}{*}{ Single instrument $(n=9)$} & Interviews $(n=4)$ \\
\hline & & Content Representation ( $n=2)$ \\
\hline & & Questionnaires $(n=2)$ \\
\hline & & Reflective Journals ( $n=1$ ) \\
\hline \multirow{3}{*}{ Quantitative approach $(n=5)$} & \multicolumn{2}{|l|}{ Multiple instrument $(n=1)$} \\
\hline & \multirow{2}{*}{ Single instrument $(n=4)$} & Questionnaires $(n=3)$ \\
\hline & & Card sorting $(n=1)$ \\
\hline \multirow{5}{*}{$\begin{array}{l}\text { Mixed Methods approach }(n \\
=18)\end{array}$} & Multiple instrument $(n=7)$ & $\begin{array}{l}\text { Most papers use questionnaires }(n=5) \text { or } \\
\text { interviews }(n=5) \text { as an instrument. }\end{array}$ \\
\hline & \multirow{4}{*}{ Single instrument $(n=11)$} & Questionnaires $(n=7)$ \\
\hline & & Tests $(n=2)$ \\
\hline & & Q-methodology $(n=1)$ \\
\hline & & Interview $(n=1)$ \\
\hline
\end{tabular}


Rolién J. V. CIRILO, Elaine A. COLAGRANDE. Instruments to access the chemistry pedagogical content knowledge: An integrative review

PROBLEMS

OF EDUCATION IN THE $21^{\text {st }}$ CENTURY Vol. 79 , No. 3, 202

As for studies of a quantitative nature, the majority used a questionnaire as an instrument of data collection. Three publications present the questionnaire as the only data collection instrument, one publication uses a card classification activity as the only instrument and in another publication, the use of multiple instruments (Questionnaires, Tests and Video Recording) is perceived.

In studies of a mixed nature, the use of questionnaires and tests as a data collection instrument prevails $(n=16)$. Eleven publications use only a single collection instrument, among which questionnaires, tests, interviews, and Q Methodology are identified. Another 7 articles use multiple instruments for data collection.

\section{f) the use of PCK models as a theoretical framework}

Regarding the adoption of specific PCK models, among those available in the scientific literature, it was possible to observe that there is a high frequency $(n=46)$ of publications that did not specifically adopt a PCK model as the theoretical framework of the research, as illustrated in Table 5:

\section{Table 5}

PCK Models Adopted in the Corpus

\begin{tabular}{ll}
\hline PCK model & $n$ \\
\hline Does not adopt & 46 \\
\hline Magnunsson et al. (1999) & 16 \\
\hline Topic-Specific Pedagogical Content Knowledge & 8 \\
\hline Technological and Pedagogical Content Knowledge & 7 \\
\hline Park and Oliver (2008) & 3 \\
\hline Consensus Model & 2 \\
\hline Grossman (1990) & 1 \\
\hline Rollnick et al. (2008) & 1 \\
\hline Hanuscin et al. (2011) and Faikhamta (2013) & 1 \\
\hline Shulman (1986) & 1 \\
\hline Gess-Newsome (1999) & 1 \\
\hline Friedrichsen et al. (2011) & 1 \\
\hline Pedagogical-Visual-Content-Knowledge & 1 \\
\hline
\end{tabular}

Among the articles that explicitly adopted a PCK model, those with the highest frequency were those by Magnunsson et al. (1999), followed by the TSPCK (Topic-Specific Pedagogical Content Knowledge) model, and TPACK (Technological and Pedagogical Content Knowledge).

\section{Discussion}

As seen, research on PCK has increased substantially since the term was proposed by Lee Shulman in 1986 and several researchers have already demonstrated this perception (Aydin \& Boz, 2013; De Jong et al., 2005; Fernandez, 2015b; Kleickmann et al., 2013). The results point to a significant increase in publications involving PCK research in Chemistry, especially in the last decade and this is in line with the results obtained by Almeida et al. (2019) in the perception of greater dissemination in the ideas initially discussed by Shulman from the last decade. The 
USA, as the country of origin of the construct, still leads the publications, according to the results exposed by this research, agreeing with the research carried out by Goes and Fernandez (2018), but, it can be observed that its dissemination is worldwide, especially in the case of partnerships established at an international level, which make up a considerable frequency of the analysed publications. This is another indication of the importance that the construct has acquired and, specifically, of how it has been widely investigated for the disciplinary field of Chemistry.

Regarding the use of a specific topic, the results indicate a tendency to link the specificity of the topics to PCK research, following the same trend pointed out by Almeida et al. (2019). The initial ideas of Shulman (1986), the study developed by Abell (2008), the model and knowledge base proposed by Azam (2019), and the very concept of the PCK proposed by Pena and Mesquita (2020) pointed to the nature of topic-specific for the PCK and the results confirm this trend. From the articles selected for analysis, a gap is identified in the scientific literature demonstrated by the lack of studies developed for the same specific topic, as well as the exploration of the most varied specific topics found in the teaching and learning processes of Chemistry. The results suggest that PCK studies on specific topics are still not enough to discuss its systematization and, therefore, it is considered an important issue to be investigated in later studies.

Regarding the diversity of specific topics present in the analysed corpus, more frequent research is recognized for the topics of electrochemistry, chemical bonds, nature of science, and chemical equilibrium, for example, and, otherwise, there are fewer occurrences for the topics of chemistry quantum, the periodic table, chemical kinetics, nuclear reactions, and analytical techniques. In the present research, no results were found from previous research in the scientific literature that addressed what are the specific topics that have been researched in the studies of the disciplinary Chemistry PCK, a fact that also offers a field for future investigations.

In addition to the topic-specific nature of the PCK, the results show that the most investigated public when dealing with PCK are teachers in practice in basic education and teachers in training, which is in line with the results obtained by Almeida et al. (2019) for PCK research, in general, in Brazil, and with the results of the research by Goes and Fernandez (2018) for PCK research in Chemistry, although, in the latter case, the authors report a scarcity of publications for the high school. Barnett and Hodson (2001) argued that experienced teachers tend to have a more organized PCK and, therefore, more open to explanation and documentation so that the teacher training process can be reflected and redesigned. It is also possible to conclude that, for the PCK in Chemistry, the results suggest the same trend pointed out by Padilla and Van Driel (2011), Padilla and Garritz (2015), Goes and Fernandez (2018), and Almeida et al. (2019), in which there is still little clarity in the PCK research in Chemistry of professors in higher education, which may reflect a barrier to both the acceptance of the construct as a potential tool for the development of the PCK in higher education and to design curriculum for training teachers at this level of education. About this fact, Shulman et al. (2006) criticize the PhDs in Education, culminating in a proposal defined by the term "Professional Practice Doctorate", the PPD, in the sense of pointing out ways for the discussion on the training of teachers to work in higher education.

There is still uncertainty regarding the use of PCK models already published in the scientific literature since the results obtained in the investigated corpus show that most of the analysed publications do not adopt a specific PCK model, confirming the same trend identified by Goes and Fernandez (2018), but with one difference: greater adherence by the academic community can be observed for the TSPCK, TPACK models and the one proposed by Park and Oliver (2008) in detriment to that of Grossman (1990) in this corpus. At this point, it should be noted that some PCK models were specifically designed to investigate science teachers (Abell, 2008; Consensus Model, created in the first PCK Summit in 2012; Magnunsson et al., 1999; 
Rolién J. V. CIRILO, Elaine A. COLAGRANDE. Instruments to access the chemistry pedagogical content knowledge: An integrative review

PROBLEMS

OF EDUCATION IN THE $21^{\text {st }}$ CENTURY Vol. 79, No. 3, 2021

392

Park \& Oliver, 2008) and which are widely used, but it can be recognized that, in the case of Chemistry teachers, a PCK model that is specific to this audience could be of a broad interest in the world academic community. Pena and Mesquita (2020) made this proposal, which is still recent, which should be considered by the academic community in the development of future studies.

As a central part of this research, the results demonstrate that among the most used instruments to explain the PCK of Chemistry in the investigations, are the interviews, the CoRe, and the field diaries, which carry with them the latent, implicit, or tacit connotation of the construct, as previously mentioned (Fernandez, 2015a ; Goes \& Fernandez, 2014; Loughran et al., 2004) and which make the qualitative character of PCK research prevail, and may also explain the lower occurrence of purely quantitative research for the thematic. On the other hand, it is necessary to consider what Kind (2009) mentions, regarding the observations of teaching practice, widely used in the publications analysed in this corpus, in which the PCK can be considered explicit, at least partially, in the practice of teachers.

The results also demonstrate that there are other instruments used to explain the PCK of Chemistry teachers, which advance the research initially carried out by Baxter and Lederman (1999) and Kind (2009), such as the use of Wiki, Q methodology, the Curricular and Professional Thinking (Martínez-Aznar et al., 2017) and the Mortimer Conceptual Profile Model (Mortimer, 1995), for example, that although they have unique occurrences in the analysed corpus, they expand the variety of available instruments for use by the academic community. Although they did not consider the methodological approaches used in the publications, the research developed by Almeida et al. (2019) and Goes and Fernandez (2018) identify the same general trend exposed in the results of this research, namely: interviews, questionnaires, CoRe, observations of the practice and reflective records were the most used instruments.

This research, through the specification of the methodological approaches, managed to advance in the understanding that the questionnaires and tests are more recurrent in the mixed research, the interviews in the qualitative research, and the questionnaires in the quantitative research. In other words, there are slight differences between the instruments that tend to be used according to the methodological approach that the research adopts.

This study enabled the establishment of a methodological overview of the research involving the investigation of the PCK of teachers in the specific disciplinary field of Chemistry. Other reviews (Almeida et al., 2019; Baxter \& Lederman, 1999; Goes \& Fernandez, 2018; Kind, 2009) sought to discuss the access methods and documentation of the PCK, but not specifically in this disciplinary field, which reveals a contribution to this research theme, in addition to being an update of the access and documentation methods already synthesized in the aforementioned reviews.

\section{Conclusions and Implications}

This integrative review research proved to be important to establish a systematization of the methodological panorama of research on the PCK of Chemistry teachers, specifically. This study intended to contribute to the update on the theme, both for researchers in the area and for those who want to have their first contact with investigations of the Chemistry PCK, to know about its use, instruments of collection and explanation of the PCK, its worldwide dissemination, among other aspects discussed above.

In an attempt to answer the questions initially proposed, it is possible to conclude that there are predominant data collection instruments in PCK research in Chemistry, but that, from the perspective of the methodological approach adopted, the frequency of use of the instruments and the instruments themselves suffer significant variations. This can contribute to a new reading for the academic public that has or will develop an interest in this area of research. 
The investigation reinforces the need to debate about the epistemological and conceptual nature of the PCK, as well as the models and knowledge bases proposed in the scientific literature, since the results indicate that most of the research studies developed do not adopt a specific PCK model as a theoretical framework and, on the other hand, there are so many other conceptions, knowledge bases and models being proposed. In this perspective, there is the idea that a specific model for the discipline of Chemistry can bring together specific contexts for the professional training of these teachers, and, perhaps, this explains the variety of models and concepts proposed for the theme.

Considering the analysed articles, the results suggest topics most frequently addressed in investigations, such as electrochemistry, chemical balance, and chemical bonds, for example, as well as a variety of other topics. Discussions about the nature of a specific topic are still quite premature because although the articles investigating the PCK of a given topic show results, there is no knowledge produced that can be considered substantial for the construction of proposals for initial and continuing teacher training and, on the other hand, there are topics that have not even been investigated in this corpus. It is also possible to notice a tendency for the investigations of the disciplinary PCK in Chemistry to be of a topic-specific character, which may have influenced, even, a specific definition of the PCKC and a specific model and knowledge base for the disciplinary field.

The investigations involving professors in practice in higher education are still little explored, which certainly reflects a lesser intensity in the discussions - highly necessary - about the development of the PCK and the professionalization of teachers of Chemistry in practice at this level of education. On the other hand, the investigations carried out in the context of the training of chemistry teachers are quite widespread and equally necessary, since they make it possible to reformulate undergraduate courses.

There is no doubt that the recognition of the teacher's value is possible, necessary, and that the Pedagogical Content Knowledge has contributed significantly to its ends, but, this is an ongoing process that should be persecuted mainly because of the scientific community's contributions made.

\section{Declaration of Interest}

Authors declare no competing interest.

\section{Acknowledgments}

CAPES - Coordenação de Aperfeiçoamento de Pessoal de Nível Superior [Coordination for the Improvement of Higher Education Personnel].

\section{References}

Abell, S. K. (2008). Twenty years later: Does pedagogical content knowledge remain a useful idea? International Journal of Science Education, 30(10), 1405-1416. https://doi.org/10.1080/09500690802187041

Almeida, P. C. A. de, Davis, C. L. F., Calil, A. M. G. C., \& Vilalva, A. M. (2019). Shulman's theoretical categories: An integrative review in the field of teacher education. Cadernos de Pesquisa, 49(174), 130-149. https://doi.org/10.1590/198053146654

Aydin, S., \& Boz, Y. (2013). The nature of integration among PCK components: A case study of two experienced chemistry teachers. Chemistry Education Research and Practice, 14(4), 615-624.

Azam, S. (2019). Distinguishing topic-specific professional knowledge from topic-specific PCK: A conceptual framework. International Journal of Environmental and Science Education, 14(5), 281-296. http://www.ijese.net/makale/2122.html 
Rolién J. V. CIRILO, Elaine A. COLAGRANDE. Instruments to access the chemistry pedagogical content knowledge: An integrative review

PROBLEMS

OF EDUCATION IN THE $21^{\text {st }}$ CENTURY Vol. 79 , No. 3, 2021

394

Bardin, L. (2011). Content Analysis. Edições, 70.

Barnett, J., \& Hodson, D. (2001). Pedagogical content knowledge: Toward a fuller understanding of what good science teachers know. Science Education, 85, 426-453. https://doi.org/10.1002/sce.1017

Baxter J.A., \& Lederman N. G. (1999). Assessment and measurement of pedagogical content knowledge. In Gess-Newsome J., \& Lederman N. G. (Eds). Examining Pedagogical Content Knowledge (Vol. 6, pp. 147-161). Kluwer Academic Publishers. https://doi.org/10.1007/0-306-47217-1

Cooper, H. M. (1982). Scientific guidelines for conducting integrative research reviews. Review of Educational Research, 52(2), 291-302. https://doi.org/10.3102/00346543052002291

Creswell, J. (2009). Research design: Qualitative, quantitative, and mixed-method approaches. Sage Publications.

Evans, R. (2007). Comments on Shulman, Golde, Bueschel, and Garabedian: Existing practice is not the template. Educational Researcher, 36(9), 553-559. https://doi.org/10.3102/0013189X07313149

Faikhamta, C. (2013). The development of in-service science teachers' understandings of and orientations to teaching the nature of science within a PCK-based NOS course. Research in Science Education 43, 847-869. https://doi.org/10.1007/s11165-012-9283-4

Fernandez, C. (2015a). Revisitando a base de conhecimentos e o conhecimento pedagógico do conteúdo (PCK) de professores de Ciências [Revisiting the knowledge base and science teachers' pedagogical content knowledge]. Ensaio Pesquisa em Educação em Ciências, 17(2), 500-528. https://dx.doi.org/10.1590/1983-21172015170211

Fernandez, C. (2015b). Knowledge base for teaching and pedagogical content knowledge (PCK): Some useful models and implications for teachers' training. Problems of education in the $21^{\text {st }}$ century, 60, 79-100. http://www.scientiasocialis.lt/pec/node/906

Fernandez, C., \& Goes, L. F. (2014). Conhecimento pedagógico do conteúdo: Estado da arte no ensino de ciências e matemática [Pedagogical content knowledge: State-of-art in science and mathematics teaching]. In: Garritz, A., Lorenzo, M. G., \& Daza Rosales, S. (Org.). Conocimiento didáctico del contenido: Una perspectiva iberoamericana (pp. 65-99). Editorial Académica Española.

Fraser, S. P. (2016). Pedagogical Content Knowledge (PCK): Exploring its usefulness for science lecturers in higher education. Research in Science Education, 46, 141-161. https://doi.org/10.1007/s11165014-9459-1

Friedrichsen, P., Driel, J. H. V., \& Abell, S.K. (2011). Taking a closer look at science teaching orientations. Science Education, 95, 358-376. https://doi.org/10.1002/sce.20428

Gess-Newsome, J. (1999). Pedagogical content knowledge: An introduction and orientation. In GessNewsome, J., \& Lederman, N. G. (Eds.), Examining pedagogical content knowledge (pp. 3-17). Kluwer Academic Publishers. https://doi.org/10.1007/0-306-47217-1

Goes, L. F. (2014). Conhecimento pedagógico do conteúdo: Estado da arte no campo da educação e no ensino de química. [Pedagogical Content Knowledge: State-of-art in educational field and chemistry teaching.] Dissertation, Science Teaching (Physics, Chemistry and Biology), University of São Paulo, São Paulo. https://doi.org/10.11606/D.81.2014.tde-30042015-154835

Goes, L. F., \& Fernandez, C. (2018). Reflexões metodológicas sobre pesquisas do tipo estado da arte: Investigando o conhecimento pedagógico do conteúdo [Methodologial reflections about research type state-of-the-art: Investigating the pedagogical content knowledge]. Revista electrónica de Enseñanza de las Ciencias, 17(1), 94-118.

Grossman, P. L. (1990). The making of a teacher: Teacher knowledge and teacher education. Columbia University. Teachers' college press.

Hanuscin, D. L., Lee, M. H., \& Akerson, V. L. (2011). Elementary teachers' pedagogical content knowledge for teaching the nature of science. Science Education, 95, 145 167. https://doi.org/10.1002/sce.20404

Jong, O. D., Van Driel, J. H., \& Verloop, N. (2005), Preservice teachers' pedagogical content knowledge of using particle models in teaching chemistry. Journal of Research in Science Teaching, 42, 947964. https://doi.org/10.1002/tea.20078

Kagan, D. M. (1990). Ways of evaluating teacher cognition: Inferences concerning the Goldilocks Principle. Review of Educational Research, 60(3), 419-469. https://doi.org/10.3102\%2F00346543060003419 
Keller, M. M., Neumann, K., \& Fischer, H. E. (2017). The impact of physics teachers' pedagogical content knowledge and motivation on students' achievement and interest. Journal of Research in Science Teaching, 54, 586-614. https://doi.org/10.1002/tea.21378

Kind, V. (2009). Pedagogical content knowledge in science education: Perspectives and potential for progress.StudiesinScienceEducation, 45(2),169-204.https://doi.org/10.1080/03057260903142285

Kleickmann, T., Richter, D., Kunter, M., Elsner, J., Besser, M., Krauss, S., \& Baumert, J. (2013). Teachers' Content Knowledge and Pedagogical Content Knowledge: The role of structural differences in teacher education. Journal of Teacher Education, 64(1), 90-106. https://doi.org/10.1177/0022487112460398

Loughran, J., Mulhall, P., \& Berry, A. (2004). In search of pedagogical content knowledge in science: Developing ways of articulating and documenting professional practice. Journal of Research in Science Teaching, 41, 370-391. https://doi.org/10.1002/tea.20007

Magnusson S., Krajcik J., \& Borko H. (1999). Nature, sources, and development of Pedagogical Content Knowledge for science teaching. In Gess-Newsome, J., \& Lederman, N. G. (Eds) Examining Pedagogical Content Knowledge (Vol. 6, pp. 95-132). Kluwer Academic Publishers. https://doi.org/10.1007/0-306-47217-1

Martínez-Aznar, M. M., Rodríguez-Arteche, I., \& Gómez-Lesarri, P. (2017). La resolución de problemas professionales como referente para la formación inicial del professorado de física y química [The professional problem solving as a framework to initial teacher's training of Physics and Chemistry teachers]. Revista Eureka sobre Enseñanza y Divulgación de las Ciencias, 14(1), 162-180. https://revistas.uca.es/index.php/eureka/article/view/3017

Mortimer, E.F. (1995). Conceptual change or conceptual profile change? Science Education, 4, 267-285. https://doi.org/10.1007/BF00486624

Padilla, K., \& Van Driel, J. (2011). The relationships between PCK components: The case of quantum chemistry professors. Chemistry Education Research and Practice, 12, 367-378. https://doi.org/10.1039/C1RP90043A

Padilla, K., \& Garritz, A. (2015). Tracing a research trajectory on PCK and chemistry university professors' beliefs. In A. Berry, P. Friedrichsen, \& J. Loughran (Eds.), Re-examining Pedagogical Content Knowledge in Science Education (1 $1^{\text {st }}$ edition, pp. 75-87). Routledge. https://doi.org/10.4324/9781315735665

Park, S., \& Oliver, J.S. (2008). Revisiting the Conceptualisation of Pedagogical Content Knowledge (PCK): PCK as a conceptual tool to understand teachers as professionals. Research in Science Education 38, 261-284. https://doi.org/10.1007/s11165-007-9049-6

Pena, G. B. O., \& Mesquita, N. S. A. (2020). Conhecimento pedagógico do conteúdo de química (PCKC): Conhecimento profissional específico para a docência em química [Chemistry Pedagogical Content Knowledge (PCKC): Professional specific knowledge for teaching chemistry]. In Faleiro, W., Vigário, A. F., \& Felicio, C. M. (Orgs.), Entre fios e tramas da formação inicial e continuada de professores (vol. 3, pp. 304-329). KELPS.

Rollnick, M., Bennett, J., Rhemtula, M., Dharsey, N., \& Ndlovu, T. (2008). The place of subject matter knowledge in PCK - A case study of South African teachers teaching the amount of substance and equilibrium. International Journal of Science Education, 30(10), 1365-1387. https://doi.org/10.1080/09500690802187025

Russell, C. L. (2005). An overview of the integrative research review. Progress in Transplantation, 15(1), 8-13. https://doi.org/10.1177/152692480501500102

Shulman, L. S. (1986). Those who understand: Knowledge growth in teaching. Educational Researcher, 4-14. https://doi.org/10.1177\%2F002205741319300302

Shulman, L. S. (1987), Knowledge and teaching: Foundations of the New Reform. Harvard Educational Review, 57 (1), 1-23. https://doi.org/10.17763/haer.57.1.j463w79r56455411

Shulman, L., Golde, C., Bueschel, A., \& Garabedian, K. (2006). Reclaiming education's doctorates: A critique and a proposal. Educational Researcher, 35(3), 25-32. http://www.jstor.org/stable/3700104

Shulman, L. S. (2007). Response to comments: Practical wisdom in the service of professional practice. Educational Researcher, 36(9), 560-563. https://doi.org/10.3102/0013189X07313150 
Rolién J. V. CIRILO, Elaine A. COLAGRANDE. Instruments to access the chemistry pedagogical content knowledge: An integrative review

PROBLEMS

OF EDUCATION

IN THE $21^{\text {st }}$ CENTURY

Vol. $79, \frac{\text { No. } 3,2021}{396}$

Cite as: Cirilo, R. J. V., \& Colagrande, E. A. (2021). Instruments to access the chemistry pedagogical content knowledge: An integrative review. Problems of Education in the $21^{\text {st }}$ Century, 79(3), 381-396. https://doi.org/10.33225/pec/21.79.381
Rolién J. V. Cirilo

(Corresponding author)
Master's Degree Student, Federal University of Alfenas, Rua Gabriel Monteiro da Silva, 700 Centro - Alfenas/MG - Brazil.

E-mail: rolienvieira@gmail.com

ORCID: https://orcid.org/0000-0003-0361-6057

Elaine A. Colagrande
$\mathrm{PhD}$, Professor, Federal University of Alfenas, Rua Gabriel Monteiro da Silva, 700 Centro - Alfenas/MG - Brazil.

E-mail: elainecola@gmail.com

ORCID: https://orcid.org/0000-0003-3307-3524 